\title{
Factors Affecting Anatomy Learning from the Viewpoints of Medical Students at Basic Sciences Stage
}

\author{
Navid Golshani ${ }^{1}$, Bahman Mehraban ${ }^{4}$, Iraj Rashidi ${ }^{3}$, Nader Salari ${ }^{2}$ and Cyrus Jalili ${ }^{3,{ }^{*}}$ \\ ${ }^{1}$ Students Research Committee, Kermanshah University of Medical Sciences, Kermanshah, Iran \\ ${ }^{2}$ Statistics Department, Kermanshah University of Medical Sciences, Kermanshah, Iran \\ ${ }^{3}$ Fertility and Infertility Research Center, Kermanshah University of Medical Sciences, Kermanshah, Iran \\ ${ }^{4}$ English Department, Kermanshah University of Medical Sciences, Kermanshah, Iran \\ "Corresponding author: Fertility and Infertility Research Center, Kermanshah University of Medical Sciences, Kermanshah, Iran. Email: cjalili@yahoo.com
}

Received 2018 May 20; Revised 2018 October 06; Accepted 2018 October 28.

\begin{abstract}
Background: Knowledge of anatomy is the basis of medicine and clinical practices. This study aimed to determine factors affecting anatomy learning from the viewpoint of students at Kermanshah University of Medical Sciences.

Methods: This cross-sectional study enrolled all students at basic sciences stage at the School of Medicine at Kermanshah University of Medical Sciences in 2016 and 2017. A questionnaire was delivered in classrooms by the researchers with the permission of the teachers. Data was analyzed in the SPSS-16 software, employing the Mann-Whitney and Kruskal-Wallis tests.

Results: Out of 300 questionnaires, 179 were returned, 71 from male students (39.7\%) and 108 from female students (60.3\%); 116 (64.8\%) in the third semester, 31 (17.3\%) in the fourth, and 32 (17.9\%) in the physiopathology level. Significant differences were found between the viewpoints of male and female students on the following variables: Use of animation, use of moulages, questions based on references, frequent quizzes, classified tests during the term, and the teachers' patience, indicating the 'clear expression of teachers' with a mean of $4.7 \pm 0.47$ as the main effective factor. There were significant differences between the mean scores for 'design of questions based on the sources' $(\mathrm{P}<0.05)$ and also between the views of physiopathology students and third-year students $(\mathrm{P}<$ 0.05).

Conclusions: Lecture-based education without proper audio-visual aids lacks popularity among students, resulting in a waste of time and low levels of student learning. Mentioning the clinical aspects and engaging students in clinical issues to improve learning is paramount.
\end{abstract}

Keywords: Anatomy Learning, Medical Students, Kermanshah

\section{Background}

Knowledge of anatomy is the basis of medicine with a direct relationship to clinical practices, hence playing a pivotal role in every therapeutic practice, especially for surgical specialties $(1,2)$. In the late 20 th century, dissection was the cornerstone of medical education. Similarly today, determining the exact anatomical location of the lesion is essential to its effective treatment by the physician. Therefore, it is imperative for surgeons and all those who deal with invasive procedures on patients to have sufficient knowledge of anatomy. Since this sort of knowledge is the prerequisite for proper diagnosis and referrals to other specialists, it has a critical role in establishing a thorough examination by the physician (3). The importance of anatomy in clinical situations can be perceived in other ways too. From 1995 to 2000, the number of cases relating to errors in anatomic pathology brought to the Medical De- fense Union increased by sevenfold. Recently, 32 percent of cases in general and vascular surgery referred to this Union have been included in the category of "injury to deep structures" (4). Medical education consists of different methods, including lectures, dissection, fixed dissected samples, models and moulages, superficial anatomy, and radiologic anatomy (5). Teachers of anatomy use different techniques, too. Despite the specific pros and cons of each method, it has been noted that medical students learn the vast knowledge of anatomy more efficiently in practical sessions, with the help of audio-visual aids $(6,7)$. A study showed that complementing education in basic sciences with modern methods, especially mentioning their relationship with clinical issues, enhances the students' motivation to learn (8). Another study reported that holding the practical anatomy sessions ahead of the theoretical ones improved student learning (9). Another study on first-year students concluded that problem-based learning 
increased student motivation and learning in comparison with the lecturing method (10). The following factors in another study were found to be the most effective for learning anatomy in decreasing order of significance from the viewpoint of students: Using moulages, teachers' appropriate expression, use of clinical points during teaching, reviewing theoretical subjects in practical sessions, and using educational pictures (11). Another study showed that students considered the following as positively affecting learning anatomy: Reviewing theoretical subjects in practical sessions, U-shaped arrangement of seats in the class, holding practical sessions, final evaluation in combined forms, administration of quizzes, increasing the time of practical sessions, promoting the instructors' methods of teaching, holding anatomy classes from 8 to 10 a.m., and summarizing the topics at the end of each session by the instructor (12). Limitations in access to cadaver and advances in education with computers have dramatically changed the teaching of anatomy. Three-dimensional contents especially designed to simulate juxtaposition of different body parts are extremely beneficial in teaching anatomy (13).

The final aim of any methods or means of teaching anatomy is the students' optimal understanding and promotion of learning; therefore, student opinions on education are highly important and can significantly help instructors improve their teaching. Further to similar studies in other universities $(6,8,9,11,12)$, this study aimed to determine factors affecting anatomy learning from the viewpoints of students at Kermanshah University of Medical Sciences.

\section{Methods}

This cross-sectional study enrolled all students at basic sciences stage in the School of Medicine at Kermanshah University of Medical Sciences in 2016 and 2017. The statistical population included all students at basic sciences level having passed at least 6 credits of anatomy courses. The instrument in this study, the questionnaire of factors affecting anatomy learning from the viewpoints of students, was designed by Mehralizadeh et al. (11) in order to determine factors influencing anatomy learning from the viewpoints of students at Semnan University of Medical Sciences. The reliability of the questionnaire has been approved by Spearman's correlation coefficient $(r=0.74)$. The questionnaire contains three sections: Demographics, 15 questions to assess factors affecting anatomy learning, and 15 questions on the clinical application of different sections of anatomy, the effect of study skills, the teachers evaluation methods, teaching schedule, method of studying anatomy, and its presentation model. To score the items, a scale of 1 to 5 was assigned to the answers, representing: Ineffective, very little, a little, much, and very much respectively.

The questionnaire was delivered to the students in the class by the researcher in person with the permission of the teachers. The students were asked to answer each item patiently. The questionnaires were collected by the researcher after 15 minutes. Participation was not obligatory.

The data was loaded onto SPSS-16 software to be analyzed. Descriptive and inferential statistics of MannWhitney and Kruskal-Wallis were employed for analysis.

\section{Results}

The main findings of this study indicate that from the viewpoints of medical students, the teachers' clear explanations, nice behavior toward students, use of audio-visual aids such as moulages, teachers' patience, reviewing theoretical issues in practical classes, pre-studying, and benefiting from computer-assisted teaching such as suitable slides and related animations exerted the greatest influence over anatomy learning.

A total of 179 out of 300 questionnaires were returned, comprising 71 from male participants (39.7\%) and 108 from female participants (60.3\%); 116 (64.8\%) of them were in the third semester, 31 (17.3\%) in the fourth, and 32 (17.9\%) in the physiopathology level.

Studying the views of the students on the factors influencing the learning of anatomy course from the students' point of view showed that the students identified teachers' clear expression with a mean of $4.7 \pm 0.47$ as the main effective factor for learning. The treatment of students by faculty members and the use of moulages were also the second and third most effective factors in student learning (Table 1).

Based on the results of the Mann-Whitney test, there were significant differences between the viewpoints of male and female students on the following variables: Use of animation, use of moulages, designing questions based on references, frequent classroom quizzes, classified tests during the term, and teachers' patience in the classroom (Table 2).

According to the Kruskal-Wallis statistical survey, there were significant differences between the mean scores for influencing the design of the questions based on the sources $(\mathrm{P}<0.05)$. A dual comparison with the MannWhitney test showed significant differences between the views of physiopathology students and third year students $(\mathrm{P}=0.11)$ (Table 3$)$.

\section{Discussion}

The role of teachers in any form of education is undeniable. Their clear explanations of educational materials together with their interactions with students leave the greatest impacts on learning. The findings of this study 


\begin{tabular}{|c|c|c|c|c|c|c|c|}
\hline & \multirow{2}{*}{ Factors } & \multirow{2}{*}{ Mean \pm SD } & \multicolumn{5}{|c|}{ Degree of Effect on Learning ${ }^{a}$} \\
\hline & & & Ineffective & Very Little & A Little & Much & Very Much \\
\hline $\mathbf{1}$ & Teachers' clear explanation & $4.7 \pm 0.47$ & $0(0)$ & $0(0)$ & $4(2.2)$ & $33(18.4)$ & $142(79.3)$ \\
\hline 2 & $\begin{array}{l}\text { Teachers' nice behavior toward } \\
\text { students }\end{array}$ & $4.3 \pm 0.78$ & $1(1.1)$ & $0(0)$ & $10(5.6)$ & $55(30.7)$ & $112(62.6)$ \\
\hline 3 & Use of moulages & $4.5 \pm 0.64$ & $0(0)$ & $2(1.1)$ & $9(5)$ & $59(33)$ & $109(60.9)$ \\
\hline 4 & $\begin{array}{l}\text { Teachers' patience in the } \\
\text { classroom }\end{array}$ & $4.3 \pm 0.78$ & $2(1.1)$ & $3(1.7)$ & $14(7.8)$ & $71(39.7)$ & $89(49.7)$ \\
\hline 5 & $\begin{array}{l}\text { Reviewing theoretical material } \\
\text { in practical classes }\end{array}$ & $4.3 \pm 0.76$ & $1(0.6)$ & $1(0.6)$ & $23(12.8)$ & $67(37.4)$ & $87(48.6)$ \\
\hline 6 & Pre-study & & $4(2.2)$ & $4(2.2)$ & $26(14.5)$ & $63(35.2)$ & $82(45.8)$ \\
\hline 7 & Use of animation & $4.2 \pm 0.89$ & $5(2.8)$ & $1(0.6)$ & $24(13.4)$ & $71(39.7)$ & $78(43.6)$ \\
\hline 8 & Teachers' proper appearance & $3.9 \pm 1.1$ & $14(7.8)$ & $4(2.2)$ & $30(16.8)$ & $57(31.8)$ & $74(41.3)$ \\
\hline 9 & $\begin{array}{l}\text { Use of relevant clinical points } \\
\text { during teaching }\end{array}$ & $4.1 \pm 0.84$ & $3(1.7)$ & $2(1.1)$ & $26(14.5)$ & $75(41.9)$ & $73(40.8)$ \\
\hline 10 & $\begin{array}{l}\text { Use of educational pictures in } \\
\text { slides }\end{array}$ & $4.2 \pm 0.74$ & $0(0)$ & $1(0.6)$ & $31(17.3)$ & $74(41.3)$ & $73(40.8)$ \\
\hline 11 & $\begin{array}{l}\text { Designing questions based on } \\
\text { references }\end{array}$ & $3.9 \pm 0.97$ & $8(4.5)$ & $1(0.6)$ & $37(20.7)$ & $76(42.5)$ & $57(31.8)$ \\
\hline 12 & Frequent quizzes & $3.8 \pm 1.1$ & $13(7.3)$ & $8(4.5)$ & $20(11.2)$ & $85(47.5)$ & $53(29.6)$ \\
\hline 13 & $\begin{array}{l}\text { Use of classified tests during the } \\
\text { semester }\end{array}$ & $4.03 \pm 0.88$ & $6(3.4)$ & $3(1.7)$ & $22(12.3)$ & $96(53.6)$ & $52(29.1)$ \\
\hline 14 & $\begin{array}{l}\text { Students' active participation } \\
\text { (questions and answers) }\end{array}$ & $3.7 \pm 1.08$ & $11(6.1)$ & $11(6.1)$ & $37(20.7)$ & $77(43)$ & $43(24)$ \\
\hline 15 & Lecture-based teaching & $3.7 \pm 0.96$ & $12(6.7)$ & $26(14.5)$ & $85(47.5)$ & $43(24)$ & $13(7.3)$ \\
\hline
\end{tabular}

${ }^{\mathrm{a}}$ Values are expressed as No. (\%).

Table 2. Mean and Standard Deviation of Scores For Medical Students' Viewpoints at KUMS Concerning Factors Affecting Anatomy Learning Based on Their Gender for Each Item

\begin{tabular}{|c|c|c|c|c|c|}
\hline & Factors & Males $^{\mathbf{a}}$ & Females $^{\mathbf{a}}$ & $\mathbf{Z}$ & P Value \\
\hline 1 & Use of animation & $4.01 \pm 1.03$ & $4.3 \pm 0.77$ & -2.007 & 0.045 \\
\hline 2 & Use of moulages & $4.3 \pm 0.77$ & $4.6 \pm 0.56$ & -2.802 & 0.005 \\
\hline 3 & Use of educational pictures in slides & $4.1 \pm 0.75$ & $7.2 \pm 0.73$ & -1.410 & 0.159 \\
\hline 4 & Reviewing theoretical material in practical classes & $4.2 \pm 0.76$ & $4.4 \pm 0.76$ & -1.682 & 0.093 \\
\hline 5 & Pre-study & $4.2 \pm 0.9$ & $4.2 \pm 0.94$ & -0.178 & 0.858 \\
\hline 6 & Designing questions based on references & $3.7 \pm 1.1$ & $4.1 \pm 0.8$ & -2.033 & 0.042 \\
\hline 7 & Lecture-based teaching & $3.06 \pm 0.99$ & $3.1 \pm 0.95$ & -0.495 & 0.621 \\
\hline 8 & Students' active participation & $3.6 \pm 1.04$ & $3.7 \pm 1.1$ & -0.934 & 0.350 \\
\hline 9 & Frequent classroom quizzes & $3.5 \pm 1.1$ & $4.08 \pm 1$ & -3.300 & 0.001 \\
\hline 10 & Use of classified tests during the semester & $3.8 \pm 0.99$ & $4.1 \pm 0.78$ & -2.142 & 0.032 \\
\hline 11 & Use of relevant clinical points during teaching & $4.1 \pm 0.89$ & $4.2 \pm 0.81$ & -1.09 & 0.272 \\
\hline 12 & Teachers' patience in the classroom & $4.1 \pm 0.94$ & $4.4 \pm 0.63$ & -2.48 & 0.013 \\
\hline 13 & Teachers' nice behavior toward students & $4.4 \pm 0.75$ & $4.5 \pm 0.67$ & -1.133 & 0.257 \\
\hline 14 & Teachers' proper appearance & $3.9 \pm 1.2$ & $3.9 \pm 1.1$ & -0.033 & 0.974 \\
\hline 15 & Teachers' clear explanations & $4.7 \pm 0.51$ & $4.8 \pm 0.44$ & -1.252 & 0.211 \\
\hline
\end{tabular}

${ }^{\mathrm{a}}$ Values are expressed as mean $\pm \mathrm{SD}$. 
Table 3. Mean and Standard Deviation of Scores for Medical Students' Viewpoints at Kermanshah University of Medical Sciences Concerning Factors Affecting Anatomy Learning Based on the Students' Level of Education for Each Item

\begin{tabular}{|c|c|c|c|c|c|}
\hline & Factors & $\begin{array}{c}\text { Third Semester } \\
\text { Students }\end{array}$ & $\begin{array}{c}\text { Fourth Semester } \\
\text { Students }^{\text {a }}\end{array}$ & $\begin{array}{c}\text { Physiopathology } \\
\text { Students }^{\mathrm{a}}\end{array}$ & P Value \\
\hline 1 & Use of animation & $4.2 \pm 0.88$ & $4.08 \pm 0.66$ & $4.1 \pm 1.1$ & 0.606 \\
\hline 2 & Use of moulages & $4.5 \pm 0.63$ & $4.08 \pm 0.79$ & $4.52 \pm 0.59$ & 0.050 \\
\hline 3 & Use of educational pictures in slides & $4.2 \pm 0.76$ & $4.1 \pm 0.93$ & $4.2 \pm 0.54$ & 0.999 \\
\hline 4 & Reviewing theoretical material in practical classes & $4.3 \pm 0.75$ & $4.3 \pm 0.98$ & $4.30 \pm 0.70$ & 0.871 \\
\hline 5 & Pre-study & $4.1 \pm 0.93$ & $4.3 \pm 1.1$ & $4.3 \pm 1.15$ & 0.392 \\
\hline 6 & Designing questions based on references & $4.08 \pm 0.19$ & $3.6 \pm 1.07$ & $3.4 \pm 1.1$ & 0.008 \\
\hline 7 & Lecture-based teaching & $3.1 \pm 0.94$ & $3 \pm 1.2$ & $2.9 \pm 1.02$ & 0.538 \\
\hline 8 & Students' active participation & $3.7 \pm 1.09$ & $3.9 \pm 1.2$ & $3.7 \pm 0.97$ & 0.552 \\
\hline 9 & Frequent classroom quizzes & $3.9 \pm 1.1$ & $3.7 \pm 1.05$ & $3.7 \pm 0.95$ & 0.432 \\
\hline 10 & Use of classified tests during semester & $4 \pm 0.91$ & $4.1 \pm 0.71$ & $4.1 \pm 0.77$ & 0.764 \\
\hline 11 & Use of relevant clinical points during teaching & $4.2 \pm 0.77$ & $3.8 \pm 1.3$ & $4.1 \pm 0.96$ & 0.753 \\
\hline 12 & Teachers' patience in the classroom & $4.3 \pm 0.76$ & $4.3 \pm 0.65$ & $4.2 \pm 0.99$ & 0.794 \\
\hline 13 & Teachers' nice behavior toward students & $4.5 \pm 0.66$ & $4.6 \pm 0.49$ & $4.3 \pm 0.98$ & 0.836 \\
\hline 14 & Teachers' proper appearance & $3.9 \pm 1.1$ & $4.4 \pm 0.79$ & $3.9 \pm 1.2$ & 0.420 \\
\hline 15 & Teachers' clear explanations & $4.7 \pm 0.46$ & $4.8 \pm 0.38$ & $4.6 \pm 0.57$ & 0.438 \\
\hline
\end{tabular}

${ }^{\mathrm{a}}$ Values are expressed as mean $\pm \mathrm{SD}$.

highlighted the primary significance of these factors in learning anatomy. Those findings are in line with the results of some other studies in which the students considered the teachers' eloquence and proper statements an important factor in learning anatomy $(11,14,15)$.

Among other factors influencing the teaching of anatomy is the use of moulages. Inherent difficulties in imagining anatomic structures for the first time and the incomprehensibility of theoretical explanations add to the popularity of using moulages in teaching anatomy. The results of this study and similar ones have pointed to the great effectiveness of their use in anatomy learning from the students' perspective(11). The significance of this issue can guide companies producing moulages toward developing this important tool and producing more advanced moulages.

As shown in other studies, the results of this study also indicated that from the students' point of view, reviewing theoretical issues in practical classes significantly impacts the study of anatomy $(11,12)$. This can help teachers in practical classes to seek more effective instructions with a brief review of topics in theoretical classes to ensure proper understanding.

Computers, software and related animations have found their way into medical education, and anatomy is one of the fields where there is great demand for these in order to get the meaning of those concepts across which are difficult to express through mere explanations. This study indicated that students viewed the use of slides, animations and proper pictures as influencing factors in learning, in line with the findings of other studies $(13,16$ 18). This can encourage anatomy teachers to connect with computer designers in order to produce suitable animations and software for use in their teaching.

The study also showed that another influencing factor was the mention of clinical points while teaching anatomy. The medical profession is not theoretical by nature, and the application of courses and their significance in clinical situations bears great importance for medical students. The findings of other studies have also shown that medical students in their freshman year coinsidered the learning of clinical skills as effective and encouraging in learning (19), pointing out the necessity of involving students in clinical situations. Boon et al. stated that teaching anatomy with physical examinations using computers, MRI, CT scans and radiology images enhanced student learning and encouraged them to learn and realize the role of anatomy in para-clinical situations (20). A shortcoming of the current medical education system is the lack of access to clinical settings until the physiopathology stage. Attending clinics and gaining clinical experiences might act as a motivating factor for medical students in their first and second years.

An important finding of this study which deserves further discussion concerns lecturing as an anatomy teaching method, which was ranked as the least effective one from 
the students' perspective. This finding also supports the findings of other studies. For example, in a similar study by Mehralizadeh et al. in Semnan, lecturing was recognized as the least effective teaching method by students (11). Taghavi et al. showed that using an integrated method in teaching anatomy was more effective compared to the conventional method (21). Antepohl and Herzig also indicated that students favored teaching anatomy based on the problem-solving approach (PBL); they preferred this approach to conventional lecturing (8). It is apparent that lecturing without using different educational facilities and means has little educational benefit and effectiveness. Anatomy instructors need to bear in mind that the most beneficial education consists of different methods.

In this study, there were significant differences between the viewpoints of male and female students on variables such as regular class quizzes, classified tests during the term, and teachers' patience in the classroom. The real reason for these discrepancies is not clearly understood. The study also indicated that there were no significant differences between the viewpoints of students in the third and fourth semesters and those in the physiopathology stage except for the design of questions based on references. This can be due to a broader insight of students at the physiopathology stage and their greater need for further learning.

This study had limitations such as the lack of full participation by students, which might be due to filling out many questionnaires during the term, their tiredness in the class, etc. A total of 59.66 percent of the questionnaires were completed and returned in this study. As the study was carried out on the students in the third and fourth semesters and also on those in the physiopathology stage, the findings cannot be generalized to the whole population. There is a need to research students in other stages as well. It is also suggested that similar studies be carried out in other medical universities throughout the country.

\subsection{Conclusions}

The results of this study reveal that audio-visual aids such as moulages, proper slides, use of computers and animations play a part in improving student learning. Among other effective factors are the teachers' clear explanations and their nice and friendly behavior toward the students. It is also concluded that lecture-based education without the use of proper audio-visual aid lacks popularity among the students, resulting in a waste of time and decline in student learning. Another major point was the need to mention the clinical aspects and engage students in clinical issues to improve learning. This last point plays an encouraging role in the levels of student learning.

\section{Acknowledgments}

The researchers would like to extend their appreciation to the students who participated in the study, the members of the Students Research Committee, and the teachers of the Department of Anatomy in KUMS, especially Dr. Ali Ghanbari. The study was funded by KUMS (Project Number: 97008).

\section{Footnote}

Funding/Support: The study was funded by Kermanshah University of Medical Sciences (Project Number: 97008).

\section{References}

1. Martin K, Bessell NJ, Scholten I. The perceived importance of anatomy and neuroanatomy in the practice of speech-language pathology. Anat Sci Educ. 2014;7(1):28-37. doi: 10.1002/ase.1377. [PubMed: 23775941].

2. Smith CF, Mathias H. Educational perspectives on learning anatomy: 21. J Anat. 2007;210(6):774-5.

3. Papa V, Vaccarezza M. Teaching anatomy in the XXI century: New aspects and pitfalls. ScientificWorldJournal. 2013;2013:310348. doi: 10.1155/2013/310348. [PubMed: 24367240]. [PubMed Central: PMC3842041].

4. Ellis H. Medico-legal litigation and its links with surgical anatomy. Surg Oxford Int Edit. 2002;20(8):i-ii. doi: 10.1383/surg.20.8.0.14518.

5. Kerby J, Shukur ZN, Shalhoub J. The relationships between learning outcomes and methods of teaching anatomy as perceived by medical students. Clin Anat. 2011;24(4):489-97. doi:10.1002/ca.21059. [PubMed: 20949485].

6. Rouz Behi AA, Fararooei M, Almasi A. [A study comparing the effect of educational video films with computer CDs on teaching anatomy to medical students]. Armaghan Danesh. 2001;6(23):26-31. Persian.

7. Siabani S, Moradi MR, Siabani H, Rezaei M, Siabani S, Amolaei K, et al. [Students view points on the educational problems in medical school of Kermanshah University of Medcial Sciences (2007)]. J Kermanshah Univ Med Sci. 2009;13(2 (41)):162-71. Persian.

8. Antepohl W, Herzig S. Problem-based learning versus lecture-based learning in a course of basic pharmacology: A controlled, randomized study. Med Educ. 1999;33(2):106-13. doi: 10.1046/j.13652923.1999.00289.x. [PubMed: 10211260].

9. Atlassi MA, Naderian H, Moosavi G. [Effect of anatomy practice background on quality of anatomy education]. Feyz. 2000;4(15):17-22. Persian.

10. Kermaniyan F, Mehdizadeh M, Iravani S, MArkazi Moghadam N, Shayan S. [Comparing lecture and problem-based learning methods in teaching limb anatomy to first year medical students]. Iran J Med Educ. 2008;7(2):379-88. Persian.

11. Mehralizadeh S, Pourhoseini M, Ghorbani R, Zolfaghary S. [Factors affecting learning of anatomy: Students' viewpoints]. Iran J Med Educ. 2013;13(1):49-57. Persian.

12. Fahimi Manzari S, Askarramaki S, Sam S, Pourghasem M. Effective methods on teaching and learning of anatomy course. Eudc Stragety Med Sci. 2013;6(2):95-9. doi:10.1016/j.compedu.2005.06.005.

13. Brenton H, Hernandez J, Bello F, Strutton P, Purkayastha S, Firth T, et al. Using multimedia and Web3D to enhance anatomy teaching. Computer Educ. 2007;49(1):32-53. doi: 10.1016/j.compedu.2005.06.005.

14. Ghorbani R, Haji-Aghajani S, Heidarifar M, Andade F. [Viewpoints of nursing and para-medical students about the features of a good university lecturer]. Koomesh. 2009;10(2):77-83. Persian. 
15. Vakili A, Hajaghajani S, Rashidy-Pour A, Ghorbani R. [An investigation of factors influencing student evaluation of teacher performance: A comprehensive study in Semnan University of Medical Sciences]. Koomesh. 2011:93-103. Persian.

16. Hallgren RC, Parkhurst PE, Monson CL, Crewe NM. An interactive, web-based tool for learning anatomic landmarks. Acad Med. 2002;77(3):263-5. doi:10.1097/00001888-200203000-00018. [PubMed: 11891167].

17. Nicholson DT, Chalk C, Funnell WR, Daniel SJ. Can virtual reality improve anatomy education? A randomised controlled study of a computer-generated three-dimensional anatomical ear model. Med Educ. 2006;40(11):1081-7. doi: 10.1111/j.1365-2929.2006.02611.x. [PubMed: 17054617].

18. Qayumi AK, Kurihara Y, Imai M, Pachev G, Seo H, Hoshino Y, et al. Comparison of computer-assisted instruction (CAI) versus traditional textbook methods for training in abdominal examination (Japanese experience). Med Educ. 2004;38(10):1080-8. doi: 10.1111/j.1365-2929.2004.01957.x. [PubMed: 15461653].

19. Lam TP, Irwin M, Chow LW, Chan P. Early introduction of clinical skills teaching in a medical curriculum-factors affecting students' learning. Med Educ. 2002;36(3):233-40. doi: 10.1046/j.13652923.2002.01142.x. [PubMed: 11879513].

20. Boon JM, Meiring JH, Richards PA, Jacobs CJ. Evaluation of clinical relevance of problem-oriented teaching in undergraduate anatomy at the University of Pretoria. Surg Radiol Anat. 2001;23(1):57-60. doi: 10.1007/s00276-001-0057-3. [PubMed: 11370144]

21. Taghavi MM, Vazeirinejad R, Shamsizadeh A, Shariati KM. Evaluation of medical student's learning of anatomical subjects by using a compound method and in comparison with traditional method. J Iran Anat Sci. 2011;9(35):170-7. 